\title{
Application of BARON Solver for Solution of Cost Based Unit Commitment Problem
}

\author{
Vineet Kumar and R. Naresh \\ Electrical Engineering Department \\ National Institute of Technology Hamirpur, India, \\ vineet@,nith.ac.in, rnaresh@,nith.ac.in
}

\begin{abstract}
This paper presents the solution to cost-based unit commitment (CBUC) problem with and without ramp rate limits of thermal power plants using general algebraic modelling system (GAMS) with BARON solver. The BARON solver in GAMS environment takes care of different units and system constraints to find an optimal solution. To validate the effectiveness of the proposed GAMS solution, simulations have been performed on six different systems consisting of 10-units, 20-units, 40-units, 60-units, 80-units and 100-units, respectively. The analysis also includes the valve-point loading along with the ramp rate limits of thermal units. Results obtained with BARON solver in GAMS have been compared with other approaches available in literature. Comparative analysis shows that the performance of GAMS is better as compared to other existing techniques in terms of operating cost obtained and satisfaction level of constraints.
\end{abstract}

Keywords: Unit commitment (UC), General Algebraic Modelling System (GAMS), Branch and Reduce Optimization Navigator (BARON), Ramp rate limit, Evolutionary algorithms.

\begin{tabular}{|c|c|c|c|}
\hline \multicolumn{4}{|c|}{ Nomenclature } \\
\hline $\begin{array}{ll}a_{i}, & b_{i} \\
c_{i}\end{array}$ & Thermal cost coefficient of $i^{\text {th }}$ unit & $P_{i}^{\min }$ & $\begin{array}{l}\text { Minimum generation capacity of unit } \\
i \text { in MW }\end{array}$ \\
\hline$D R_{i}$ & Ramp-down limit of unit $i$ in MW & $P_{\mathrm{i}}^{\max }$ & $\begin{array}{l}\text { Maximum generation capacity of unit } \\
i \text { in MW }\end{array}$ \\
\hline$U R_{i}$ & Ramp-up limit of $i^{\text {th }}$ unit in MW & $U_{i}^{t}$ & on/off status of unit $i$ at time $t$ \\
\hline$N$ & Number of fuel units & $S U C_{i, t}$ & $\begin{array}{l}\text { Start-up cost of unit } i \text { at } t^{\text {th }} \text { time in Rs. } \\
/ \mathrm{h}\end{array}$ \\
\hline $\begin{array}{l}F_{i} \\
\left(P_{i}^{t}\right)\end{array}$ & $\begin{array}{l}\text { Production cost of unit } i \text { at time } t \text { in } \\
\text { Rs. } / \mathrm{h}\end{array}$ & $S D C_{i, t}$ & $\begin{array}{l}\text { Shut-down cost of unit } i \text { at } t^{\text {th }} \text { time in } \\
\text { Rs. /h }\end{array}$ \\
\hline$C S C_{i}$ & Cold start-up cost of unit $i$ in Rs. $/ \mathrm{h}$ & $P_{i}^{t}$ & $\begin{array}{l}\text { Real power production of } i^{t h} \text { unit at } \\
\text { time } t \text { in MW }\end{array}$ \\
\hline$H S C_{i}$ & Hot start-up cost of unit $i$ in Rs. $/ \mathrm{h}$ & $T$ & $\begin{array}{l}\text { Amount of scheduling time horizons } \\
\text { in hours }\end{array}$ \\
\hline$P_{\text {load }}{ }^{t}$ & Power demand at $t^{\text {th }}$ time in MW & $T_{i, \text { down }}$ & $\begin{array}{l}\text { Minimum-down time limit of unit } i \text { in } \\
\text { hours }\end{array}$ \\
\hline $\mathrm{T}_{i, u p}$ & $\begin{array}{l}\text { Minimum-up time of unit } i \text { in } \\
\text { hours }\end{array}$ & $T_{i, o n}{ }^{t}$ & $\begin{array}{l}\text { Continuously-on time of } i^{\text {th }} \text { unit till } \\
\text { time } t \text { in hours }\end{array}$ \\
\hline$T_{i, \text { cold }}$ & $\begin{array}{l}\text { Cold start-up time limit of unit } i \text { in } \\
\text { hours }\end{array}$ & $T_{i, o f f}$ & $\begin{array}{l}\text { Continuously-off time of } i^{\text {th }} \text { unit till } \\
\text { time } t \text { in hours }\end{array}$ \\
\hline$I$ & Index for thermal generating units & $T$ & Index for time periods \\
\hline
\end{tabular}

\section{Introduction}

Energy was, is and will remain the basic foundation that determines the stability of economic development of any country. In economic operation of the power system, every step-in planning and scheduling of the system must lead to an absolute economy. In recent years, the world energy demand is increasing exponentially that reaches to a different peak value, therefore electric power generation utilities are under pressure to generate more and more power at the lowest

Received: September $22^{\text {nd }}, 2019$. Accepted: September $30^{\text {th }}, 2020$ DOI: $10.15676 /$ ijeei.2020.12.4.7 
possible cost. The power generating units need to be scheduled efficiently to meet hourly load demand while satisfying various unit and system constraints. In this respect, the UC problem plays a vital role and therefore, considered as an optimization task that has to be performed by the electric utilities in the daily operation, planning and control [1]. After the determination of the unit commitment status in each hour of the planning horizon, economic dispatch (ED) is performed on the set of committed thermal units to calculate their optimal generation set point. Thus, the accurate solutions of the ED and UC problems are essential in order to operate the power system in an economic and efficient manner.

Fuel cost savings can be obtained by proper/judicious commitment of the available generating units. This unit commitment problem is termed as cost-based unit commitment (CBUC) problem. The main objective of CBUC problem is to minimize the total generation cost (production cost, shutdown and start-up costs) while satisfying the various unit and system constraints. The main constraints include minimum up and down time constraints, load balance constraint, generation limits, system spinning reserve, thermal unit ramp rate limits, etc. Practically, the large steam turbines have steam admission valves that lead to non-convexity in unit production cost operation. Therefore, a practical CBUC model must consider the valve-point loading effect, however it has a significant impact on the complexity of model.

In order to solve unit commitment problem (UCP), numerous mathematical models and methods have been developed and these methods mainly include dynamic programming (DP) [2], priority list (PL) [3], mixed integer linear programming [MILP] [4-5], Lagrangian Relaxation (LR) [6], and branch and bound (BB) [7]. PL method holds the advantage of being simple and possessing high speed in comparison to other methods but it suffers from high operating cost due to constrained exploration moves in search space. DP in case of large-scale UC problems, requires huge computational time and suffers from the curse of dimensionality. MILP suffers from similar disadvantage of huge computational time and requirement of large memory size for solving large scale problems. Execution time grows exponentially in case of BB method, thus limiting its application for large scale UC problem. LR method suffers from numerical convergence and non-optimal quality of solution despite providing fast solution. The shortcomings in the above mentioned techniques led to extensive research in Meta-heuristic techniques which resulted in development of optimization methods such as genetic algorithm (GA) [8], integer coded genetic algorithm (ICGA) [9], matrix real coded genetic algorithm (MRCGA) [10], evolutionary programming (EP) [11], multi agent evolutionary programming priority list (MAEP-PL) [12], simulated annealing (SA) [13], memory simulated annealing (MSA) [14], differential evolution (DE) [15], discrete binary differential evolution (DBDE) [16], quantum inspired evolutionary algorithm (QEA) [17], bacterial foraging algorithm(BFA) [18], shuffled frog leaping algorithm (SFLA) [19], imperialistic competition algorithm (ICA) [20], particle swarm optimization (PSO) [21], hybrid particle swarm optimization with mixed integer programming (PSO-ILA) [22], improved binary particle swarm optimization (IBPSO) [23], time varying acceleration coefficient particle swarm optimization (TVAC-PSO) [24], harmony search algorithm (HSA) [25], modified differential evolution (MDE) [26], invasive weed optimization (IWO) approach [27] and binary gravitational search algorithm (BGSA) [28].

Apart from above mentioned individual approaches, a number of hybrid approaches were also investigated which consist of DP and ANN [29], Fuzzy, DP and SA [30], gradient-based modified teaching learning optimizer with black hole algorithm (GMTLBO-BH) [31], hybrid Taguchi-ant colony system algorithm (HTACS) [32], new binary decomposition approach (NBD) [33], hybrid artificial bee colony algorithm [34], binary real artificial bee colony (BRABC) [35], novel binary artificial bee colony with local search (NBABC-LS) [36] and modified novel binary artificial bee colony with genetic crossover (MBABC-GC)[37], with the primary goal of optimizing search space for large systems. Based on the above literature review, motivation is to develop a computationally strong approach, which can achieve the realistic optimum results in a reasonable execution time and simultaneously satisfying the diverse time dependent limits for the large scale UCP. While conducting the literature survey, we learned that the research work related with valve point loading effect included in unit commitment is not yet 
available and here in this paper, the authors have considered and successfully implemented the solution technique to achieve results for such unit commitment problem.

A paper presented by Debabrata Chattopadhyay on application of GAMS gives a thorough knowledge regarding GAMS language and its application to power system optimization problems, comprising of a small test system of three generators having piecewise linear cost characteristics [38]. This paper discussed the GAMS model structure for economic dispatch, unit commitment and generation investment planning. From the literature survey it is observed that GAMS software has not been applied to solve the cost-based unit commitment problem with diverse system constraints and also considering convex and non-convex cost characteristics. As in [38] a small test system was considered and minimum up and minimum down time constraints were ignored, therefore the work reported here is the modelling of the large size unit commitment problem including minimum up and minimum down time constraints using General Algebraic Modelling System (GAMS) in cost-based unit commitment (CBUC). GAMS is a high-level model development environment that supports the analysis and solution of non-linear and mixed integer linear optimization problems. GAMS is an accurate and powerful tool which can be easily applied for large and complex optimization problem. In this paper, the authors have attempted to include all diverse constraints such as power balance constraints, minimum up and minimum down constraints, spinning reserve, ramp rate constraints, load demand and initial status etc. while solving the problem. In this work, the effectiveness of the proposed algorithm is demonstrated on six test systems having 10-units, 20-units, 40-units, 60-units, 80-units and 100units, while considering non-linearity in cost characteristics of the systems.

\section{CBUC Problem Formulation}

In a power system, the UC problem comprises of several sub-problems ranging from linear programming problems to complex non-linear problems. The UC problem is about minimizing the thermal cost of generating units for a definite period of operation so as to accomplish optimal generation dispatch among operating power units and in return satisfying the system demand considering power system operational constraints [3].

The objective function corresponding to the production cost can be approximated to have a quadratic cost characteristic as well as non-linear and non-convex cost characteristic due to valve-point loading of the thermal units. Mathematically, objective function is represented by eq. (1) as [36]:

$$
T G C=\min \sum_{i=1}^{N} \sum_{t=1}^{T}\left\{F_{i}\left(P_{i}^{t}\right) U_{i}^{t}+U_{i}^{t}\left(1-U_{i}^{t-1}\right) S U C_{i, t}+U_{i}^{t-1}\left(1-U_{i}^{t}\right) S D C_{i, t}\right\}
$$

where,

$$
S U C_{i, t}=\left\{\begin{array}{l}
H S C_{i}, \text { if } T_{i, \text { down }} \leq T_{i, \text { off }}^{t} \leq T_{i, \text { down }}+T_{i, \text { cold }} \\
\operatorname{CSC}_{i}, \text { if } T_{i, \text { off }}^{t}>T_{i, \text { down }}+T_{i, \text { cold }}
\end{array}\right\}
$$

where, total generation cost is denoted by $T G C$ and $S D C$ is considered as zero.

Case 1:

$$
F_{i}\left(P_{i}^{t}\right)=a_{i}+b_{i} P_{i}^{t}+c_{i}\left(P_{i}^{t}\right)^{2}
$$

Case 2:

$$
\begin{aligned}
& F_{i}\left(P_{i}^{t}\right)=a_{i}+b_{i} P_{i}^{t}+c_{i}\left(P_{i}^{t}\right)^{2}+F^{V P E}\left(P_{i}^{t}\right) \\
& \text { where } \\
& F^{V P E}=\left|e_{i} \sin \left(f_{i}\left(P_{i}^{\text {min }}-P_{i}^{t}\right)\right)\right|
\end{aligned}
$$

Here, $V P E$ is valve point loading effect. In practical power system, when steam admission valve opens, the fuel cost increases suddenly due to the wire drawing effect. It makes the problem non-differentiable in nature. Therefore, in order to make the production cost of thermal 
generators suitable for real power system problem, VPE is used [39]. The effect of VPE for multivalve steam turbine is modelled by a rectified sine curve. The sinusoidal term considered in Case 2 causes ripples to heat rate curve and therefore it creates more local minima in search space. The VPE for Case 2 is linearized which is as follows:

$$
F^{V P E}=\sum_{m=1}^{K_{i}}\left[b_{m, i}^{V P E} \cdot P_{m, i}^{t}+c_{m . i}^{V P E} \cdot U_{m, i}^{t}\right]
$$

subject to :

$$
\begin{aligned}
& P_{i}^{t}=\sum_{m=1}^{K_{i}} P_{m, i}^{t} \cdot U_{m, i}^{t} \\
& P_{m, i, t}^{\min } U_{m, i}^{t} \leq P_{m, i}^{t} \leq P_{m, i, t}^{\mathrm{max}} U_{m, i}^{t} \\
& \sum_{m=1}^{K_{i}} U_{m, i}^{t}=1
\end{aligned}
$$

where, $b_{m, i}^{V P E}$ and $c_{m . i}^{V P E}$ are linearized VPE coefficients, $P_{m, i}^{t}$ is output power of $i^{\text {th }}$ thermal unit falls to segment $m$ at time $t, U_{m, i}^{t}$ is binary variable, $m$ is index of linear segment and $K_{i}$ is total segment on piecewise linear coefficient $V P E, P_{m, i, t}^{\min }$ and $P_{m, i, t}^{\max }$ are modified minimum and maximum power limits. Parameters of above stated Case $2 b_{m, i}^{V P E}, c_{m . i}^{V P E}$ and $K_{i}$ is stated as:

$$
\begin{aligned}
& K_{i}=\operatorname{ceil}\left(\frac{M \times f_{i} \times\left(P_{i, t}^{\max }-P_{i, t}^{\min }\right)}{\pi}\right) \\
& b_{m . i}^{V P E}=\frac{F^{V P E}\left(P_{m, i, t}^{\max }\right)-F^{V P E}\left(P_{m, i, t}^{\min }\right)}{P_{m, i, t}^{\max }-P_{m, i, t}^{\min }} \\
& c_{m . i}^{V P E}=F^{V P E}\left(P_{m, i, t}^{\min }\right)-b_{m . i}^{V P E}\left(P_{m, i, t}^{\min }\right)
\end{aligned}
$$

Here, value of $M$ is taken as 2 .

$$
\begin{aligned}
& P_{m, i, t}^{\max }=\left\{\begin{array}{l}
P_{i, t}^{\min }+\frac{m \cdot \pi}{M \cdot f_{i}} ; m=1,2, . ., K_{i}-1 \\
P_{i, t}^{\max } ; m=K_{i}
\end{array}\right\} \\
& P_{m, i, t}^{\min }=P_{i, t}^{\min }+\frac{(m-1) \cdot \pi}{M \cdot f_{i}} ; m=1,2, . ., K_{i}
\end{aligned}
$$

In this paper, various constraints considered in CBUC problem are

\section{A. System balance power constraint}

At each hour, the generated power output of committed units must satisfy the power demand in the forecasted time period and is given as [37]:

$$
\sum_{i=1}^{N} P_{i}^{t} U_{i}^{t}-P_{\text {load }}^{t}=0 ; t=1,2, \ldots T
$$




\section{B. Ramp rate constraint}

The maximum limit by which the generator output power can be augmented in a certain time duration is determined by ramp-based constraint and is represented as [29]:

$P_{i}^{t}-P_{i}^{t-1} \leq U R(i)$ when generation increases

$P_{i}^{t-1}-P_{i}^{t} \leq D R(i)$ when generation decreases

\section{Unit minimum up and down time constraints}

The time constrained unit commitment (TCUC) problem includes non-linear constraints like minimum up time and minimum down time for every unit. Thus, it indicates that when in running mode, a unit should not be turned off immediately and once in off state, it should not be turned on without a minimum delay in time period, as expressed below [36]:

$$
\begin{aligned}
& \left(T_{i, \text { on }}^{t-1}-T_{i, \text { up }}\right) \times\left(U_{i}^{t-1}-U_{i}^{t}\right) \geq 0 ; \\
& \left(T_{i, \text { off }}^{t-1}-T_{i, \text { down }}\right) \times\left(U_{i}^{t}-U_{i}^{t-1}\right) \geq 0 ; \\
& i=1,2, \ldots, N ; t=1,2, \ldots T
\end{aligned}
$$

\section{Spinning reserve}

Spinning reserve is expressed as a pre-specified amount or a certain percentage of the forecasted maximum demand, and it must be available during the planning period. It is supplied by the devices that are synchronized to the power network and are capable of affecting the generator's watt power and is expressed by the eq. (18) shown below [36]:

$$
\sum_{i=1}^{N} P_{i, t}^{\max } U_{i}^{t} \geq P_{\text {load }}^{t}+S R^{t}
$$

where, $P_{i, t}^{\max }$ is maximum generation limit, $P_{\text {load }}^{t}$ is power demand and $S R^{t}$ is system spinning reserve at time $t$. Also, the spinning reserve capacity is considered during on state of a generating unit.

Unit generation limit constraint

Generation limit is used to commit a unit which must be within specified limits as shown below [40]:

$$
P_{i, t}^{\min } U_{i}^{t} \leq P_{i}^{t} \leq P_{i, t}^{\max } U_{i}^{t}
$$

where, $P_{i, t}^{\max }$ is maximum generation limit and $P_{i, t}^{\min }$ is minimum generation limit.

\section{Solution Methodology}

The UC problem formulated in section 2 is a nonlinear and mixed integer optimization problem which can be modelled using GAMS, a quite useful approach to establish an accurate model. Simultaneous development, solution and maintenance of models is possible by maintaining the same GAMS model file [41]. Sets, data, variable, equation, model and output forms the basic structure of a mathematical model and the solution procedures in GAMS.

In order to obtain best solution of nonlinear algebraic programs (NLPs) and mixed-integer nonlinear programs (MINLPs), a computational system known as Branch-and-Reduce Optimization Navigator (BARON) can be employed. Traditional NLP and MINLP algorithms converge to global optima under assumptions of certain convexity. While BARON implements deterministic global optimization techniques of the branch-and-bound type that under fairly general assumptions provide global optima, which is guaranteed. The assumption made in the above-mentioned approach is the existence of a fixed lower and upper limit on nonlinear expressions in the NLP or MINLP to be solved. Algorithm of the branch-and-bound type is implemented by BARON, improved with a range of constraint propagation and duality techniques in order to reduce the ranges of variables in the course of the algorithm. BARON's 
solver status, model status and other details of solver are given in [42]. The algorithm followed by BARON solver is presented in Figure 1.

The global minimization problem considered here in the equation 1:

Problem $P$ :

Min $f(x)$ subjected to $g(x) \leq 0, x € X$

where $f: X €$ any continuous or discrete value and $g: X €$ any continuous or discrete value.

Let $R$ be the relaxation of original problem $P$, relaxation is easier for MINLP problem rather than to solve MINLP problem.

The algorithm for proposed BARON solver is as follows:

Step 1:Initialization

Put $R$ on a list ACTIVE (list that has not been pruned) of sub-problems. Select the convergence parameter $\delta$. Also, set $L=-\inf$ and $U=+$ inf. Set $i$ (iteration) $=1$

Step 2: Termination rule

If there was a condition satisfying between $U_{i}-L_{i} \leq \delta$ or $A C T I V E=\phi$ (means at all nodes there is no feasible solution exists) then stop and the current best solution $x^{i}$ optimal is found.

Step 3: Selection Rule

Select an ACTIVE list which has a lower bound in ACTIVE sub problems.

Step 4: Sub-division rule.

choose $R_{i}$ from $A C T I V E$ according to selection rule and set $A C T I V E:=A C T I V E \backslash\left\{R_{i}\right\}$ (i.e. delete $R_{i}$ from $A C T I V E$ ).

Step 5: Range reduction technique

Tighten variable bounds as much as possible for $R_{i}$ using both feasibility-based range reduction and optimality-based range reduction tests. These tighter variable bounds imply tighter relaxation which helps in faster convergence because there are a greater number of constraints in the test problem.

Step 6: Lower and upper bounding.

Solve $R_{i}$ or bound its solution from below. Let $L_{i}$ be this lower bound. A common modification, in addition to maintaining lower bound from relaxation, maintains an upper bound on optimal objective.

Apply local heuristic search and rounding entries of values $x^{i}$, to nearest integer, and solve optimization problem with this fixed value, to find a better feasible solution for $P$, if successful. Lower bound is $L_{i}{ }^{*}=$

$\min \left\{L_{i}: i=1,2, \ldots\right\}$; upper bound is $U_{i}{ }^{*}=\min \{f(x), x \in$ any continuous and discrete values $\}$;

Step 7: Pruning rule

Remove all the infeasible nodes i.e. (prune node) where solution doesn't exist means delete all nodes except $A C T I V E$ list.

Step 8: Set $i=i+1$; go to step 2 .

The algorithm involves a search tree. The tree is divided into simple subproblems (relaxations) which are solved at every single node of the tree. The solution to every subproblem provides lower bounds, $L_{i}$ which can be used to prune nodes in the search tree from further consideration, by comparing these lower bounds to the best current upper bound $U$. The global minimum always lies between the minimum lower bound $L$ and the value $U$ of the best-found optimal solution. In the flowchart the authors have used some tolerance limits such as Reslim, absolute gap and relative gap. When $U$ and $L$ bound are equal then relative gap becomes zero so, it is also a termination criterion. The Reslim parameter used in the flowchart indicated that the execution of the BARON software will be terminated if it runs equal to 10,000 seconds. The absolute gap mentioned in the flowchart is the absolute value of the difference between upper bound and lower bound. The BARON software will terminate if the absolute gap value reduces 
below $\left(1^{*} 10^{\wedge}-6\right)$. The flowchart depicting proposed GAMS-BARON solution technique for CBUC along with constraints is presented in Figure 2.



Figure 2. Flowchart depicting proposed BARON solver in GAMS environment solution technique for CBUC problem

The BARON solver has been used first time to solve complicated mixed integer unit commitment problem without and with valve point loading for six different test systems ranging from 10 units to 100 units. This kind of research work has not yet been reported in literature.

\section{Results and Discussion}

The effectiveness of the proposed BARON solver in GAMS environment technique for CBUC is tested on two case studies based on six test systems namely: 10, 20, 40, 60, 80 and 100 fuel units over $24-\mathrm{h}$ scheduling time horizon with 1 -h time interval. The case studies are as follows.

Case study 1: with and without considering ramp rate limits on six test systems.

Case study 2: with and without ramp rate limits considering valve point loading effect on six test systems.

The complete data related to basic 20-units, 24-hour system is specified from appendix and hourly load balance is mentioned in appendix. The data values are approximately scaled up for rest of the five instances. The program file is written in GAMS 25.1 and executed on Intel core i5, $4 \mathrm{GHz}$ processor $\mathrm{PC}$. 


\section{A. Case study I}

Table 1. Optimum UC schedule for 20-unit, 24-h test system in the absence of ramp rate limit

\begin{tabular}{|c|c|c|c|c|c|c|c|c|c|c|c|c|c|c|c|c|c|c|}
\hline \multirow{2}{*}{$T$} & \multicolumn{18}{|c|}{ Generating units Power (MW) } \\
\hline & 1 and 2 & 3 and 4 & 5 and 6 & 7 & 8 & 9 & 10 & $\begin{array}{c}11 \text { and } \\
12\end{array}$ & 13 & 14 & 15 & 16 & 17 & 18 & 19 & 20 & $F_{i}\left(P_{i}^{t}\right)$ & $S U C_{i, t}$ \\
\hline 1 & 455 & 245 & 0 & 0 & 0 & 0 & 0 & 0 & 0 & 0 & 0 & 0 & 0 & 0 & 0 & 0 & 27366.25 & 0 \\
\hline 2 & 455 & 295 & 0 & 0 & 0 & 0 & 0 & 0 & 0 & 0 & 0 & 0 & 0 & 0 & 0 & 0 & 29109.02 & 0 \\
\hline 3 & 455 & 382.5 & 0 & 0 & 0 & 25 & 0 & 0 & 0 & 0 & 0 & 0 & 0 & 0 & 0 & 0 & 33111.25 & 900 \\
\hline 4 & 455 & 455 & 0 & 0 & 0 & 40 & 40 & 0 & 0 & 0 & 0 & 0 & 0 & 0 & 0 & 0 & 37195.32 & 900 \\
\hline 5 & 455 & 455 & 0 & 0 & 130 & 25 & 25 & 0 & 0 & 0 & 0 & 0 & 0 & 0 & 0 & 0 & 39457.23 & 560 \\
\hline 6 & 455 & 425 & 130 & 0 & 130 & 25 & 25 & 0 & 0 & 0 & 0 & 0 & 0 & 0 & 0 & 0 & 44188.86 & 2220 \\
\hline 7 & 455 & 455 & 130 & 0 & 130 & 45 & 45 & 0 & 0 & 0 & 0 & 0 & 0 & 0 & 0 & 0 & 46039.96 & 0 \\
\hline 8 & 455 & 455 & 130 & 130 & 130 & 30 & 30 & 0 & 0 & 0 & 0 & 0 & 0 & 0 & 0 & 0 & 48300.66 & 1100 \\
\hline 9 & 455 & 455 & 130 & 130 & 130 & 97.5 & 97.5 & 20 & 25 & 0 & 0 & 0 & 0 & 0 & 0 & 0 & 53798.76 & 1200 \\
\hline 10 & 455 & 455 & 130 & 130 & 130 & 162 & 162 & 33 & 25 & 25 & 10 & 10 & 0 & 0 & 0 & 0 & 60049.08 & 640 \\
\hline 11 & 455 & 455 & 130 & 130 & 130 & 162 & 162 & 73 & 25 & 25 & 10 & 10 & 10 & 10 & 0 & 0 & 63686.1 & 120 \\
\hline 12 & 455 & 455 & 130 & 130 & 130 & 162 & 162 & 80 & 25 & 25 & 43 & 43 & 10 & 10 & 10 & 10 & 67620.3 & 120 \\
\hline 13 & 455 & 455 & 130 & 130 & 130 & 162 & 162 & 33 & 25 & 25 & 10 & 10 & 0 & 0 & 0 & 0 & 60049.08 & 0 \\
\hline 14 & 455 & 455 & 130 & 130 & 130 & 97.5 & 97.5 & 20 & 0 & 25 & 0 & 0 & 0 & 0 & 0 & 0 & 53798.76 & 0 \\
\hline 15 & 455 & 455 & 130 & 130 & 130 & 30 & 30 & 0 & 0 & 0 & 0 & 0 & 0 & 0 & 0 & 0 & 48300.66 & 0 \\
\hline 16 & 455 & 310 & 130 & 130 & 130 & 25 & 25 & 0 & 0 & 0 & 0 & 0 & 0 & 0 & 0 & 0 & 43027.33 & 0 \\
\hline 17 & 455 & 260 & 130 & 130 & 130 & 25 & 25 & 0 & 0 & 0 & 0 & 0 & 0 & 0 & 0 & 0 & 41283.66 & 0 \\
\hline 18 & 455 & 360 & 130 & 130 & 130 & 25 & 25 & 0 & 0 & 0 & 0 & 0 & 0 & 0 & 0 & 0 & 44774.09 & 0 \\
\hline 19 & 455 & 455 & 130 & 130 & 130 & 30 & 30 & 0 & 0 & 0 & 0 & 0 & 0 & 0 & 0 & 0 & 48300.66 & 0 \\
\hline 20 & 455 & 455 & 130 & 130 & 130 & 162 & 162 & 43 & 0 & 0 & 10 & 10 & 10 & 10 & 0 & 10 & 60961.03 & 640 \\
\hline 21 & 455 & 455 & 130 & 130 & 130 & 105 & 105 & 20 & 0 & 0 & 0 & 0 & 10 & 0 & 0 & 0 & 53870.27 & 0 \\
\hline 22 & 455 & 417.5 & 130 & 130 & 0 & 0 & 25 & 20 & 0 & 0 & 0 & 0 & 0 & 0 & 0 & 0 & 44577.15 & 0 \\
\hline 23 & 455 & 432.5 & 0 & 0 & 0 & 0 & 25 & 0 & 0 & 0 & 0 & 0 & 0 & 0 & 0 & 0 & 34862.54 & 0 \\
\hline 24 & 455 & 345 & 0 & 0 & 0 & 0 & 0 & 0 & 0 & 0 & 0 & 0 & 0 & 0 & 0 & 0 & 30854.85 & 0 \\
\hline & & & & & & tal of & ating & $($ Rs. $)=$ & 982.8 & & & & & & & & 1114582.87 & 8400 \\
\hline
\end{tabular}


BARON method (GAMS) is applied to the 20 -unit test system in the presence and absence of ramp rate limits considering the quadratic cost characteristics with $10 \%$ spinning reserve hourly load. Optimum UC operation for 20-unit, 24-h test system in the absence of ramp rate limit is presented in Table 1 wherein the zero entries indicate the off status of units and total operating cost is the sum of the production and start-up costs, given in last two columns. Total operating cost obtained with BARON algorithm is obtained and compared with the cost obtained with existing methods reported in literature and are specified in Table 2. Here it can be observed that the operating cost obtained using GAMS is Rs. 1122983 which is Rs. 314 less as compared to MBABC-GC technique.

The unit status along with the generation level for 20-unit system in the absence of ramp rate limit determined using BARON solver is shown in Table 1 . The same test system with same input data was solved by using MBABC-GC whose results can be referred from Table IV in [37]. The difference in the status of units by these two methods is presented here. Unit 5 turns ON during hour $22^{\text {nd }}$ with BARON solver, however it keeps itself in shut down state in MBABC-GC algorithm. Unit 6 turns ON during hours $6^{\text {th }}, 7^{\text {th }}$ and $22^{\text {nd }}$ with BARON solver, however it keeps itself in shut down state during these time intervals in MBABC-GC algorithm. Unit 7 remains in ON state in MBABC-GC algorithm while it keeps OFF in BARON method during $5^{\text {th }}, 6^{\text {th }}, 7^{\text {th }}$ hour. Unit 8 is ON in BARON solver while it is OFF in MBABC-GC during $5^{\text {th }}$ time interval. $9^{\text {th }}$ unit remains ON in MBABC-GC technique whereas it keeps itself in OFF mode in BARON solver during $22^{\text {nd }}$ and $23^{\text {rd }}$ time period. Unit 10 remains $\mathrm{ON}$ during hour $23^{\text {rd }}$ in BARON solver while it is OFF in MABC-GC approach. Unit 16 keeps itself OFF at hour $21^{\text {st }}$ with BARON solver while MBABC-GC keeps this unit $\mathrm{ON}$ during this time interval. Unit 17 is $\mathrm{ON}$ at hour $21^{\text {st }}$ with BARON solver while MBABC-GC keeps this unit OFF during this time interval. Unit 19 keeps itself OFF at hour 20 with BARON solver while MBABC-GC puts this unit ON in this time interval. Unit 20 remains in ON state at hour 20 with BARON solver while MBABC-GC keeps this OFF in this time interval. Start-up cost for MBABC-GC and BARON solver is same i.e. Rs. 8400. Different status of units between the proposed BARON approach and MBABC$\mathrm{GC}$ approach resulted in lower operating cost, while satisfying all the constraints so as to keep the power mismatch to zero. Both the approaches satisfy all the diverse constraints i.e. minimum up and minimum down time constraints, cold hour time, spinning reserve, start-up cost, generation limits, power balance limits, therefore power violation is zero. It can also be deduced that for higher test units BARON method produces better optimal solution, presented in Table 2.

Table 2. Comparison of cost (Rs.) obtained by BARON solver with other methods

\begin{tabular}{|l|c|c|c|c|c|c|}
\hline \multirow{2}{*}{ Methods } & \multicolumn{7}{|c|}{ Number of generating units } \\
\cline { 2 - 7 } & 10 & 20 & 40 & 60 & 80 & 100 \\
\hline NBD [33] & - & - & - & - & - & 5600537 \\
\hline ILA [5] & 565828 & 1125997 & 2248285 & 3368950 & 4492173 & 5612686 \\
\hline QM [5] & 565828 & 1125997 & 2248285 & - & - & - \\
\hline EPL [2] & 563977 & 1124369 & 2246508 & 3366210 & 4489322 & 5608840 \\
\hline SA [13] & 565828 & 1126251 & 2250063 & - & 4498076 & 5617876 \\
\hline MSA [14] & 563938 & 1124273 & 2247224 & 3367499 & 4492402 & 5613330 \\
\hline GA [8] & 565825 & 1126243 & 2251911 & 3376625 & 4504933 & 5627437 \\
\hline LR [6] & 565825 & 1130660 & 2258503 & 3394066 & 4526022 & 5657277 \\
\hline ICGA [9] & 566404 & 1127244 & 2254123 & 3378108 & 4498943 & 5630838 \\
\hline MRCGA [10] & 565244 & 1125035 & 2246622 & 3367366 & 4489964 & 5610031 \\
\hline EP [11] & 564551 & 1125494 & 2259093 & 3371611 & 4498479 & 5623885 \\
\hline QEA [17] & 563938 & 1123607 & 2245557 & 3366676 & 4488470 & 5609550 \\
\hline IBPSO [23] & 563977 & 1125216 & 2248581 & 3367865 & 4491083 & 5610293 \\
\hline TVACPSO [24] & 563938 & 1123759 & 2245000 & 3365250 & 4487407 & 5607938 \\
\hline
\end{tabular}




\begin{tabular}{|l|c|c|c|c|c|c|}
\hline DBDE [16] & 563977 & 1123998 & 2245631 & 3366502 & 4488225 & 5808603 \\
\hline DE [15] & 563938 & 1124291 & 2246274 & 3365784 & 4488450 & 5607900 \\
\hline MDE [26] & 563937 & 1123407 & 2243463 & 3365553 & 4486081 & 5608287 \\
\hline BFA [18] & 564842 & 1124892 & 2246223 & 3369237 & 4491287 & 5611514 \\
\hline SFLA [19] & 564769 & 1123261 & 2246005 & 3368257 & 4503928 & 5624526 \\
\hline ICA [20] & 563938 & 1124274 & 2247078 & 3371722 & 4497919 & 5617913 \\
\hline HSA [25] & 564368 & 1127177 & 2250968 & 3375138 & 4500745 & 5633350 \\
\hline BGSA [28] & 563937 & 1123996 & 2246445 & 3364665 & 4488039 & 5607838 \\
\hline BRABC [35] & 563938 & - & - & - & - & - \\
\hline FuzZy SADP [30] & 563978 & 1123390 & 2244334 & 3366975 & 4490844 & 5610217 \\
\hline GMTLBO-BH [31] & 563938 & 1123297 & 2245602 & - & - & 5611105 \\
\hline PSO-ILA [22] & 565828 & 1125997 & 2248285 & 3368050 & 4492173 & 5612686 \\
\hline MAEP-PL [12] & 564073 & - & - & - & - & - \\
\hline NBABC [36] & 563977 & 1124556 & 2245511 & 3366377 & 4488661 & 5608327 \\
\hline NBABC-LS [36] & 563937 & 1123297 & 2243255 & 3364336 & 4487012 & 5606564 \\
\hline MBABC-GC [37] & 563938 & 1123297 & 2243996 & 3364076 & 4486528 & 5605748 \\
\hline BARON & 563937 & 1122983 & 2241285 & 3360882 & 4480816 & 5592789 \\
\hline
\end{tabular}

All decimals are rounded off to the nearest integers for all cost values and '-' sign shows that value is not available.

From Table 2, it is also observed that earlier MBABC-GC technique was providing better cost values in comparison to all other methods reported in literature. However, with the proposed approach the percentage improvement in the cost results over the MBABC-GC technique is found to be $0.0279 \%$ for 20 units, $0.120 \%$ for 40 units, $0.094 \%$ for 60 units, $0.127 \%$ for 80 units and $0.231 \%$ for 100 units. In UC, time does not play a significant role because scheduling and planning is done before 24-hour time period. So, in this paper operating cost has been considered as a major concern. Figures 3(a) and 3(b) illustrate the electric energy generated during the day and total operating cost for 20-unit test system without ramp rate limits respectively. Figure 3(a), shows that the unit 1, 2, 3 and 4 generate maximum power and are utilized throughout the day. The energy obtained in the absence of ramp rate limits for unit 1, 2, 3, 4, 5, 6, 7, 8, $910,11,12$, $13,14,15,16,17,18,19$ and 20 is 10920, 10920, 9842.5, 9842.5, 2210, 2210, 1950, 2210, 1435, $1460,342,342,125,125,83,83,40,30,10$ and $20 \mathrm{MWh}$, respectively. It is observed from Figure 3(a), that units 1, 2, 3 and 4 taken together generate maximum energy among all units. The energy generated by these four units is $41525 \mathrm{MWh}$, which is $76.61 \%$ of the total energy generated by all the units taken together over a day. This result is obvious as these are large size units having higher efficiency. From Figure 3(b), it is evident that the power demand of 1400 MW during first hour presents the lowest operating cost while demand of $3000 \mathrm{MW}$ during $12^{\text {th }}$ hour presents the highest operating cost. Therefore, it can be concluded that higher the load demand higher is the operating cost and vice-versa.

Optimum UC schedule for 20-unit, 24-h test system in the presence of ramp rate limit is presented in Table 3 wherein the zero entries indicate the off status of units and total operating cost is the sum of the production and start-up cost, given in last two columns. Ramp rate values for each hour are taken as 91, 91, 91, 91, 26, 26, 26, 26, 33, 33, 16, 16, 17, 17, 11, 11, 11, 11, 11 and $11 \mathrm{MW} / \mathrm{hr}$ respectively. From Table 3, it can be deduced that the total operating cost for 20unit test system in the presence of ramp rate limit is Rs. 1125932 and operating cost value obtained by other methods reported in literature. 

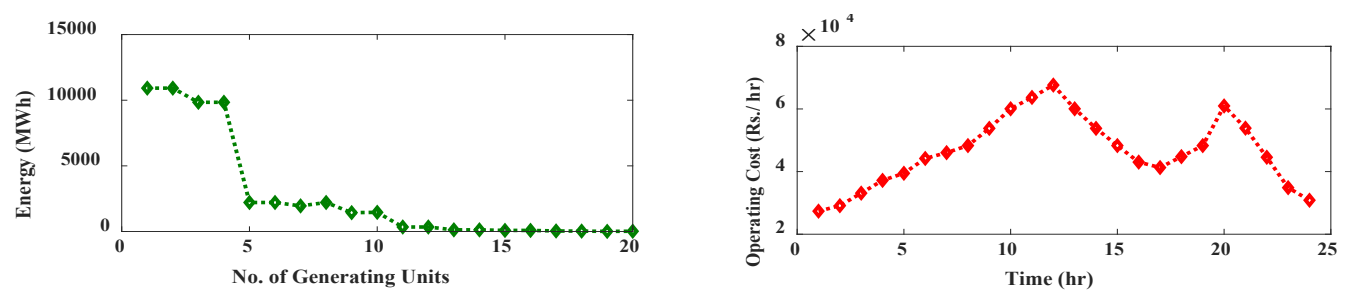

(a)

(b)

Figure 3. Optimum UC schedule for 20-unit, 24-h test system without ramp rate limit (a) Energy generated by each unit per day (b) Operating cost of each unit in a day

Table 3. Optimum UC schedule for 20-unit, 24-h test system in the presence of ramp rate limit

\begin{tabular}{|c|c|c|c|c|c|c|c|c|c|c|c|c|c|c|c|c|c|c|c|}
\hline \multirow[b]{2}{*}{$T$} & \multicolumn{19}{|c|}{ Generating units Power (MW) } \\
\hline & $\begin{array}{c}1 \\
\text { and } \\
2\end{array}$ & $\begin{array}{c}3 \\
\text { and } \\
4\end{array}$ & 5 & 6 & 7 & 8 & 9 & 10 & $\begin{array}{c}11 \\
\text { and } \\
12\end{array}$ & 13 & 14 & 15 & 16 & 17 & 18 & 19 & 20 & $F_{i}\left(P_{i}^{t}\right)$ & SUC \\
\hline 1 & 455 & 245 & 0 & 0 & 0 & 0 & 0 & 0 & 0 & 0 & 0 & 0 & 0 & 0 & 0 & 0 & 0 & 27366.26 & 0 \\
\hline 2 & 455 & 295 & 0 & 0 & 0 & 0 & 0 & 0 & 0 & 0 & 0 & 0 & 0 & 0 & 0 & 0 & 0 & 29109 & 0 \\
\hline 3 & 455 & 382.5 & 0 & 0 & 0 & 0 & 0 & 25 & 0 & 0 & 0 & 0 & 0 & 0 & 0 & 0 & 0 & 33111.23 & 900 \\
\hline 4 & 455 & 455 & 0 & 0 & 0 & 0 & 40 & 40 & 0 & 0 & 0 & 0 & 0 & 0 & 0 & 0 & 0 & 37195.34 & 900 \\
\hline 5 & 455 & 455 & 0 & 0 & 130 & 0 & 25 & 25 & 0 & 0 & 0 & 0 & 0 & 0 & 0 & 0 & 0 & 39457.24 & 560 \\
\hline 6 & 455 & 455 & 0 & 130 & 130 & 0 & 55 & 55 & 0 & 0 & 0 & 0 & 10 & 0 & 0 & 0 & 0 & 43550.14 & 1160 \\
\hline 7 & 455 & 455 & 130 & 130 & 130 & 0 & 45 & 45 & 0 & 0 & 0 & 0 & 0 & 0 & 0 & 0 & 0 & 46039.98 & 1100 \\
\hline 8 & 455 & 422 & 130 & 130 & 130 & 130 & 63 & 63 & 0 & 0 & 0 & 0 & 0 & 0 & 0 & 0 & 0 & 48468.22 & 1120 \\
\hline 9 & 455 & 437.5 & 130 & 130 & 130 & 130 & 96 & 96 & 39 & 0 & 25 & 0 & 0 & 0 & 0 & 0 & 0 & 54025.43 & 1200 \\
\hline 10 & 455 & 455 & 130 & 130 & 130 & 130 & 129 & 129 & 55 & 25 & 25 & 21 & 21 & 0 & 0 & 0 & 0 & 60318.52 & 640 \\
\hline 11 & 455 & 455 & 130 & 130 & 130 & 130 & 162 & 162 & 71 & 25 & 25 & 12 & 12 & 10 & 10 & 0 & 0 & 63843.01 & 120 \\
\hline 12 & 455 & 455 & 130 & 130 & 130 & 130 & 162 & 162 & 80 & 34 & 34 & 23 & 23 & 21 & 21 & 10 & 10 & 67834.23 & 120 \\
\hline 13 & 455 & 455 & 130 & 130 & 130 & 130 & 129 & 129 & 64 & 25 & 25 & 12 & 12 & 0 & 0 & 0 & 0 & 60265.43 & 0 \\
\hline 14 & 455 & 428.5 & 130 & 130 & 130 & 130 & 96 & 96 & 48 & 25 & 0 & 0 & 0 & 0 & 0 & 0 & 0 & 54121.73 & 0 \\
\hline 15 & 455 & 422 & 130 & 130 & 130 & 130 & 63 & 63 & 0 & 0 & 0 & 0 & 0 & 0 & 0 & 0 & 0 & 48468.22 & 0 \\
\hline 16 & 455 & 331 & 108 & 108 & 126 & 126 & 30 & 30 & 0 & 0 & 0 & 0 & 0 & 0 & 0 & 0 & 0 & 43072.1 & 0 \\
\hline 17 & 455 & 260 & 130 & 130 & 130 & 130 & 25 & 25 & 0 & 0 & 0 & 0 & 0 & 0 & 0 & 0 & 0 & 41283.65 & 0 \\
\hline 18 & 455 & 342.2 & 130 & 130 & 130 & 130 & 58 & 27.6 & 0 & 0 & 0 & 0 & 0 & 0 & 0 & 0 & 0 & 44865 & 0 \\
\hline 19 & 455 & 409.2 & 130 & 130 & 130 & 130 & 91 & 60.6 & 0 & 0 & 0 & 0 & 0 & 0 & 0 & 0 & 0 & 48540.43 & 0 \\
\hline 20 & 455 & 455 & 130 & 130 & 130 & 130 & 124 & 93.6 & 51.2 & 0 & 0 & 55 & 55 & 10 & 10 & 10 & 0 & 61570.8 & 640 \\
\hline 21 & 455 & 455 & 130 & 130 & 130 & 130 & 119 & 60.6 & 35.2 & 0 & 0 & 0 & 0 & 0 & 10 & 0 & 0 & 53982.91 & 0 \\
\hline 22 & 455 & 455 & 0 & 0 & 0 & 130 & 152 & 58 & 20 & 0 & 0 & 0 & 0 & 0 & 0 & 0 & 0 & 44345.7 & 0 \\
\hline 23 & 455 & 432.5 & 0 & 0 & 0 & 0 & 0 & 25 & 0 & 0 & 0 & 0 & 0 & 0 & 0 & 0 & 0 & 34862.51 & 0 \\
\hline 24 & 455 & 345 & 0 & 0 & 0 & 0 & 0 & 0 & 0 & 0 & 0 & 0 & 0 & 0 & 0 & 0 & 0 & 30854.84 & 0 \\
\hline & & & & & & & $\mathrm{al} \mathrm{op}$ & g cos & .) $=112$ & 1.56 & & & & & & & & 1117471.5 & 8460 \\
\hline
\end{tabular}


The unit status along with the generation level for 20 -unit system in the presence of ramp rate limit has been determined using BARON solver and is shown in Table 3 . The same test system with same input data was solved by using MBABC-GC whose results can be referred from Table VII in [37]. The comparison in the status of units by these two methods is explained here. Unit 5 turns ON during hour 6 with MBABC-GC, however it keeps itself in shut down state with BARON solver, while unit 6 turns ON with BARON solver and keeps itself in shut down state during hour 6 in MBABC-GC approach. Likewise, unit 7 remains ON in MBABCGC algorithm while it keeps OFF in BARON method during $22^{\text {nd }}$ hour. Unit 8 is in shut down state in BARON solver while it is ON in MBABC-GC during $6^{\text {th }}$ and $7^{\text {th }}$ time interval. Unit 9 is $\mathrm{ON}$ in MBABC-GC technique whereas it is in OFF mode in BARON solver during $3^{\text {rd }}$ and $23^{\text {rd }}$ time period. $10^{\text {th }}$ unit keeps itself $\mathrm{ON}$ in BARON solver, however it keeps itself in shut down state in MBABC-GC technique during $3^{\text {rd }}, 22^{\text {nd }}$ and $23^{\text {rd }}$ hour. Unit 14 at $9^{\text {th }}$ hour with MBABC$\mathrm{GC}$ is in shut down state while it is ON in BARON solver. Likewise, at hour 14 in MBABC-GC unit 14 is in OFF state while it keeps itself ON with BARON solver, and at hours 18, 19 and 20, with MBABC-GC approach this unit is ON while with BARON it keeps itself in OFF state. Unlike MBABC-GC approach, unit 16 keeps itself $\mathrm{ON}$ at hour 6, unit 18 keeps its status $\mathrm{ON}$ at $20^{\text {th }}$ and $21^{\text {st }}$ hour and unit 19 keeps ON at $20^{\text {th }}$ hour with BARON solver while this unit is OFF in MBABC-GC during these time intervals. Start-up cost for MBABC-GC is Rs. 8560 whereas with BARON solver it is Rs. 8460. Different status of units between the proposed approach and MBABC-GC approach resulted in lower operating cost, while satisfying all the constraints so as to keep the power mismatch to zero. It is observed that earlier MBABC-GC [37] technique was providing better cost values in comparison to all other methods reported in literature. With the proposed approach the percentage improvement in the cost results over the MBABC-GC technique is $0.062 \%$ for 20 units, $0.204 \%$ for 40 units, $0.252 \%$ for 60 units, $0.150 \%$ for 80 units and $0.340 \%$ for 100 units. Figures $4(\mathrm{a})$ and $4(\mathrm{~b})$ illustrate the electric energy generated during the day and total operating cost for 20 -unit test system with ramp rate limits respectively. Figure 4(a) shows that the unit 1,2, 3 and 4 generate maximum power and are utilized throughout the day. The energy generated in the presence of ramp rate limits for unit 1, 2, 3, 4, 5, 6, 7, 8, 9, 10, $11,12,13,14,15,16,17,18,19$ and 20 is $10920,10920,9757.4,9757.4,1928,2058,2206$, 1946, 1664, 1470.4, 463.4, 463.4, 134, 134, 123, 133, 41, 51, 20 and $10 \mathrm{MWh}$, respectively. It is observed from Figure 4 (a), that 4 units i.e. unit 1, unit 2, unit 3 and unit 4 generate maximum energy among all units. The energy generated by these four units is $41354.8 \mathrm{MWh}$, which is $76.3 \%$ of the total energy generated by all the units taken together over a day. This result is obvious as these are large size units having higher efficiency. From Figure 4(b), it is evident that the power demand of $1400 \mathrm{MW}$ during first hour presents the lowest operating cost while demand of $3000 \mathrm{MW}$ during $12^{\text {th }}$ hour presents the highest operating cost. Therefore, it can be concluded that higher the load demand higher is the operating cost and vice-versa. From Figure 5(b), it is clearly seen that available maximum online capacity (MOC) of units closely follows the demand including spinning reserve except 15-19 hours where minimum up and down constraints of some units are binding. Difference is MOC minus demand considering spinning reserve has also been depicted in Figure 5.

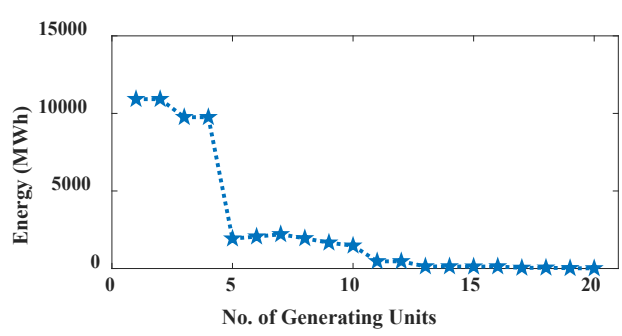

(a)

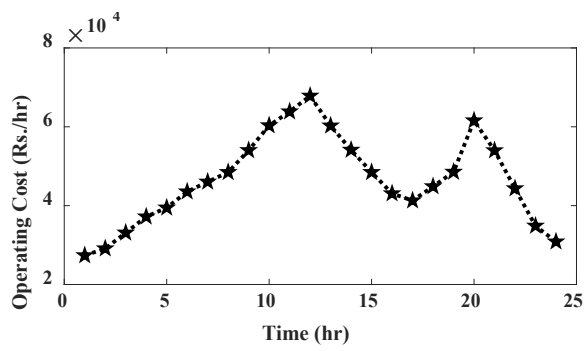

(b)

Figure 4. Optimum UC schedule for 20-unit, 24-h test system with ramp rate limit (a) Energy generated by each unit per day (b) Operating cost of each unit in a day 
B. Case study 2

BARON method (GAMS) is applied to the 20-unit test system in the presence and absence of ramp rate limits considering the valve point loading effect with $10 \%$ spinning reserve at hourly load. The data referred for analysis is given in appendix and hourly load demand is mentioned is appendix. Optimum UC schedule for 20-unit, 24-hour test system in the absence of ramp rate limit considering valve point loading effect is presented in Table 4.

Table 4. Optimum UC schedule for 20-unit, 24-h test system considering valve point loading effect and without ramp rate limit

\begin{tabular}{|c|c|c|c|c|c|c|c|c|c|c|c|c|c|c|c|c|c|c|c|c|}
\hline \multirow[b]{2}{*}{$T$} & \multicolumn{20}{|c|}{ Generating units Power (MW) } \\
\hline & 1 & 2 & 3 & 4 & 5 & 6 & 7 & 8 & 9 & 10 & 11 & 12 & 13 & 14 & 15 & 16 & 17 & 18 & 19 & 20 \\
\hline 1 & 455 & 383.2 & 324.5 & 237.3 & 0 & 0 & 0 & 0 & 0 & 0 & 0 & 0 & 0 & 0 & 0 & 0 & 0 & 0 & 0 & 0 \\
\hline 2 & 440.6 & 414 & 320.8 & 324.6 & 0 & 0 & 0 & 0 & 0 & 0 & 0 & 0 & 0 & 0 & 0 & 0 & 0 & 0 & 0 & 0 \\
\hline 3 & 426.2 & 399.7 & 404.3 & 408.1 & 0 & 0 & 0 & 0 & 61.7 & 0 & 0 & 0 & 0 & 0 & 0 & 0 & 0 & 0 & 0 & 0 \\
\hline 4 & 411.9 & 455 & 400.6 & 404.3 & 0 & 0 & 0 & 0 & 94.1 & 134.1 & 0 & 0 & 0 & 0 & 0 & 0 & 0 & 0 & 0 & 0 \\
\hline 5 & 404.7 & 440.6 & 396.9 & 400.6 & 129.6 & 0 & 0 & 0 & 126.5 & 101.1 & 0 & 0 & 0 & 0 & 0 & 0 & 0 & 0 & 0 & 0 \\
\hline 6 & 393.5 & 426.2 & 393.1 & 396.9 & 103.6 & 129.6 & 130 & 0 & 159 & 68.1 & 0 & 0 & 0 & 0 & 0 & 0 & 0 & 0 & 0 & 0 \\
\hline 7 & 455 & 411.9 & 455 & 393.1 & 114.1 & 130 & 104 & 0 & 136.4 & 100.5 & 0 & 0 & 0 & 0 & 0 & 0 & 0 & 0 & 0 & 0 \\
\hline 8 & 440.6 & 407.4 & 451.2 & 389.4 & 124.7 & 104 & 116.3 & 130 & 103.4 & 133 & 0 & 0 & 0 & 0 & 0 & 0 & 0 & 0 & 0 & 0 \\
\hline 9 & 426.2 & 455 & 447.5 & 385.7 & 130 & 114.5 & 128.6 & 117.6 & 135.8 & 162 & 20 & 52.1 & 25 & 0 & 0 & 0 & 0 & 0 & 0 & 0 \\
\hline 10 & 429.7 & 440.6 & 443.8 & 455 & 130 & 125.1 & 130 & 129.8 & 162 & 129 & 20 & 36.1 & 25 & 57.1 & 43.4 & 43.4 & 0 & 0 & 0 & 0 \\
\hline 11 & 455 & 426.2 & 440.1 & 451.4 & 104.5 & 130 & 130 & 130 & 162 & 161.4 & 20 & 52.1 & 25 & 72.1 & 54.4 & 32.4 & 10 & 43.4 & 0 & 0 \\
\hline 12 & 447.6 & 455 & 436.3 & 447.5 & 115.1 & 122.3 & 130 & 130 & 162 & 162 & 20 & 68.2 & 25 & 85 & 43.4 & 21.4 & 10 & 32.4 & 43.4 & 43.4 \\
\hline 13 & 433.3 & 440.6 & 432.6 & 443.9 & 125.6 & 130 & 104.5 & 130 & 162 & 161.7 & 20 & 80 & 25 & 68 & 32.4 & 10.4 & 0 & 0 & 0 & 0 \\
\hline 14 & 455 & 426.2 & 428.9 & 440.1 & 130 & 130 & 116.8 & 104 & 130 & 130 & 20 & 64 & 25 & 0 & 0 & 0 & 0 & 0 & 0 & 0 \\
\hline 15 & 440.6 & 411.9 & 425.1 & 436.3 & 104 & 104 & 129.2 & 116.3 & 97 & 135.6 & 0 & 0 & 0 & 0 & 0 & 0 & 0 & 0 & 0 & 0 \\
\hline 16 & 426.2 & 403.4 & 334.1 & 345.3 & 114.5 & 78 & 103.2 & 128.6 & 64 & 102.7 & 0 & 0 & 0 & 0 & 0 & 0 & 0 & 0 & 0 & 0 \\
\hline 17 & 416.1 & 389 & 330.4 & 341.6 & 88.5 & 88.5 & 77.2 & 102.6 & 96.4 & 69.7 & 0 & 0 & 0 & 0 & 0 & 0 & 0 & 0 & 0 & 0 \\
\hline 18 & 418.9 & 451.3 & 326.7 & 425.1 & 99.1 & 99.1 & 89.5 & 114.9 & 63.4 & 102 & 0 & 0 & 0 & 0 & 0 & 0 & 10 & 0 & 0 & 0 \\
\hline 19 & 452.9 & 436.9 & 410.2 & 421.4 & 109.6 & 109.6 & 101.8 & 127.2 & 95.9 & 134.5 & 0 & 0 & 0 & 0 & 0 & 0 & 0 & 0 & 0 & 0 \\
\hline 20 & 438.5 & 455 & 406.5 & 421.1 & 120.1 & 120.1 & 114.1 & 101.2 & 128.3 & 162 & 52.1 & 52.1 & 85 & 57.1 & 43.4 & 43.4 & 0 & 0 & 0 & 0 \\
\hline 21 & 424.2 & 440.6 & 402.7 & 417.3 & 94.1 & 130 & 126.4 & 113.6 & 109.8 & 129 & 36.1 & 36.1 & 68 & 72.1 & 0 & 0 & 0 & 0 & 0 & 0 \\
\hline 22 & 410.2 & 426.2 & 399 & 413.6 & 0 & 130 & 100.4 & 0 & 142.3 & 0 & 20.1 & 52.1 & 51 & 55.1 & 0 & 0 & 0 & 0 & 0 & 0 \\
\hline 23 & 455 & 430.6 & 395.3 & 409.8 & 0 & 0 & 0 & 0 & 109.3 & 0 & 0 & 0 & 0 & 0 & 0 & 0 & 0 & 0 & 0 & 0 \\
\hline 24 & 386.1 & 416.2 & 391.5 & 406.2 & 0 & 0 & 0 & 0 & 0 & 0 & 0 & 0 & 0 & 0 & 0 & 0 & 0 & 0 & 0 & 0 \\
\hline
\end{tabular}


All decimals are rounded off to the nearest integers for all power values.

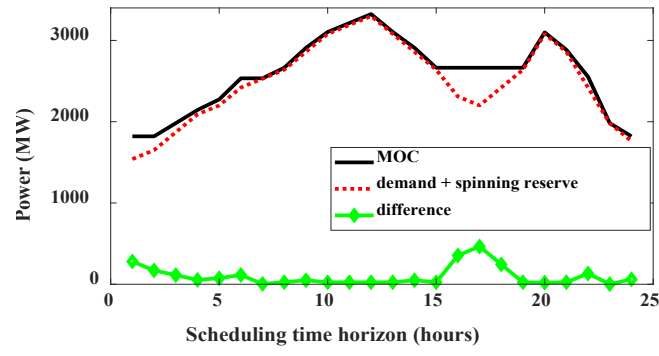

(a)

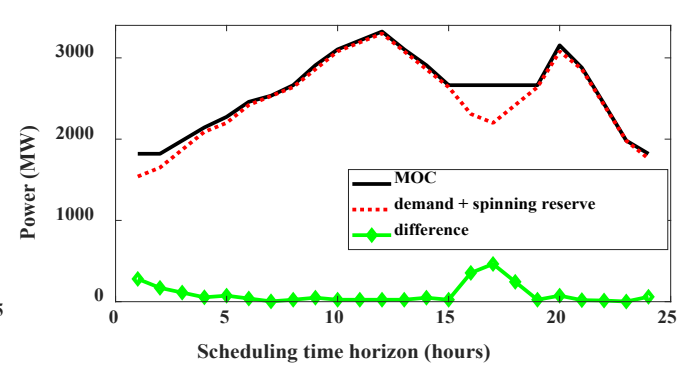

(b)

Figure 5. Comparison between available total online capacity of units and demand considering spinning reserve for the 20-unit, 24-hour system for Case study 1 (a) without ramp rate constraints and (b) with ramp rate constraints

The unit status along with the generation level for 20-unit system in the absence of ramp rate limit determined using BARON solver considering valve point coefficients is shown in Table 4. The status of units by the proposed BARON algorithm is explained briefly here. Unit 1 to unit 4 remain ON continuously for complete 24 -h time period. Unit 5 is ON at hour $5^{\text {th }}$ to hour $21^{\text {st }}$ due to minimum up and minimum down time constraints, while unit 6 and unit 7 are ON with BARON solver during hour $6^{\text {th }}$ to hour $22^{\text {nd }}$. Unit 8 keeps itself in ON state from hour $8^{\text {th }}$ to hour $21^{\text {st }}$ with BARON solver while unit 9 remains ON during $3^{\text {rd }}$ to $23^{\text {rd }}$ time period continuously. Unit 10 keeps itself $\mathrm{ON}$ at hour $4^{\text {th }}$ to hour $21^{\text {st }}$ whereas Unit 11 to 13 are in ON state at time interval 9 to interval 14 and also at hour $20^{\text {th }}, 21^{\text {st }}$ and hour $22^{\text {nd }}$. Coming to unit 14,15 and 16 , they remain ON from hour $10^{\text {th }}$ to hour $13^{\text {th }}$ and hour $20^{\text {th }}$. But unit 14 is $\mathrm{ON}$ at hour $21^{\text {st }}$ and hour $22^{\text {nd }}$ as compared to unit 15 and unit 16 which are in OFF state. Units 17-20 are ON at hour $12^{\text {th }}$ also and this is because of high load demand during this period. But unit 17 and unit 18 remain in ON state at hour $11^{\text {th }}$ while unit 19 and 20 are OFF during that time. Unit 17 is in ON state at hour $18^{\text {th }}$ while unit 18,19 and unit 20 are in OFF state during this time interval. Different status of units by the proposed BARON approach resulted in lower value of operating cost, while satisfying all the diverse constraints so as to keep the power mismatch to zero. The start-up cost obtained without ramp rate is Rs. 9070.

Optimum UC schedule for 20-unit, 24-h test system in the presence of ramp rate limit is shown in Table 5. Ramp rate values for each hour are taken as 91, 91, 91, 91, 26, 26, 26, 26, 33, $33,16,16,17,17,11,11,11,11,11$ and $11 \mathrm{MW} / \mathrm{hr}$ respectively. 
Table 5. Optimum UC schedule for 20-unit, 24-h test system in the presence of ramp rate limit

\begin{tabular}{|c|c|c|c|c|c|c|c|c|c|c|c|c|c|c|c|c|c|c|c|c|}
\hline \multirow{2}{*}{$T$} & \multicolumn{20}{|c|}{ Generating units Power (MW) } \\
\hline & 1 & 2 & 3 & 4 & 5 & 6 & 7 & 8 & 9 & 10 & 11 & 12 & 13 & 14 & 15 & 16 & 17 & 18 & 19 & 20 \\
\hline 1 & 383.2 & 455 & 324.5 & 237.3 & 0 & 0 & 0 & 0 & 0 & 0 & 0 & 0 & 0 & 0 & 0 & 0 & 0 & 0 & 0 & 0 \\
\hline 2 & 414 & 440.6 & 320.8 & 324.6 & 0 & 0 & 0 & 0 & 0 & 0 & 0 & 0 & 0 & 0 & 0 & 0 & 0 & 0 & 0 & 0 \\
\hline 3 & 399.7 & 426.2 & 404.3 & 320.8 & 0 & 0 & 0 & 0 & 149 & 0 & 0 & 0 & 0 & 0 & 0 & 0 & 0 & 0 & 0 & 0 \\
\hline 4 & 411.3 & 411.9 & 400.6 & 404.3 & 0 & 0 & 0 & 0 & 116 & 155.9 & 0 & 0 & 0 & 0 & 0 & 0 & 0 & 0 & 0 & 0 \\
\hline 5 & 404.1 & 397.5 & 396.9 & 400.6 & 129.6 & 0 & 0 & 0 & 148.4 & 122.9 & 0 & 0 & 0 & 0 & 0 & 0 & 0 & 0 & 0 & 0 \\
\hline 6 & 455 & 455 & 393.1 & 396.9 & 103.6 & 0 & 96.6 & 58.3 & 151.6 & 89.9 & 0 & 0 & 0 & 0 & 0 & 0 & 0 & 0 & 0 & 0 \\
\hline 7 & 440.6 & 440.6 & 455 & 393.1 & 114.1 & 0 & 108.9 & 70.6 & 154.8 & 122.3 & 0 & 0 & 0 & 0 & 0 & 0 & 0 & 0 & 0 & 0 \\
\hline 8 & 426.2 & 426.2 & 451.3 & 389.4 & 124.7 & 93.1 & 121.2 & $\begin{array}{l}82.9 \\
\end{array}$ & 130.2 & 154.8 & 0 & 0 & 0 & 0 & 0 & 0 & 0 & 0 & 0 & 0 \\
\hline 9 & 411.9 & 422.1 & 447.5 & 455 & 98.7 & 103.6 & 130 & 95.2 & 97.1 & 121.8 & 80 & 52.1 & 85 & 0 & 0 & 0 & 0 & 0 & 0 & 0 \\
\hline 10 & 455 & 419.3 & 443.8 & 451.3 & 109.2 & 114.1 & 104 & 107.6 & 129.6 & 154.1 & 64 & 36.1 & 68 & 57.1 & 43.4 & 43.4 & 0 & 0 & 0 & 0 \\
\hline 11 & 440.6 & 404.9 & 455 & 447.5 & 119.7 & 124.7 & 116.3 & 119.9 & 162 & 154 & 49.6 & 52.1 & 51 & 40.1 & 0 & 32.4 & 43.4 & 43.4 & 0 & 43.4 \\
\hline 12 & 455 & 455 & 455 & 455 & 130 & 130 & 130 & 130 & 162 & 162 & 65.7 & 68.1 & 34 & 25 & 14.6 & 21.4 & 32.4 & 32.4 & 10 & 32.4 \\
\hline 13 & 455 & 455 & 455 & 455 & 130 & 130 & 130 & 130 & 138.2 & 138.2 & 49.6 & 52.1 & 25 & 25 & 0 & 10.5 & 0 & 21.4 & 0 & 0 \\
\hline 14 & 440.6 & 440.6 & 451.3 & 451.3 & 104 & 104 & 130 & 130 & 110.8 & 110.8 & 33.5 & 68.1 & 0 & 25 & 0 & 0 & 0 & 0 & 0 & 0 \\
\hline 15 & 426.2 & 426.2 & 447.5 & 447.5 & 78 & 114.5 & 130 & 104 & 82.7 & 143.4 & 0 & 0 & 0 & 0 & 0 & 0 & 0 & 0 & 0 & 0 \\
\hline 16 & 411.9 & 411.9 & 356.5 & 356.5 & 75.3 & 88.5 & 123.2 & 116.3 & 49.7 & 110.2 & 0 & 0 & 0 & 0 & 0 & 0 & 0 & 0 & 0 & 0 \\
\hline 17 & 405.8 & 397.5 & 352.8 & 265.5 & 85.8 & 99.1 & 97.2 & 128.6 & 25 & 142.7 & 0 & 0 & 0 & 0 & 0 & 0 & 0 & 0 & 0 & 0 \\
\hline 18 & 442.3 & 455 & 349.1 & 349.1 & 96.3 & 109.6 & 109.5 & 121.8 & 57.7 & 109.6 & 0 & 0 & 0 & 0 & 0 & 0 & 0 & 0 & 0 & 0 \\
\hline 19 & 427.9 & 440.6 & 432.6 & 432.6 & 106.9 & 120.1 & 83.5 & 130 & 90.4 & 135.4 & 0 & 0 & 0 & 0 & 0 & 0 & 0 & 0 & 0 & 0 \\
\hline 20 & 424.9 & 426.2 & 428.9 & 428.9 & 117.4 & 130 & $\begin{array}{l}95.8 \\
\end{array}$ & 130 & 122.8 & 162 & 52.1 & 80 & 57.1 & 57.1 & 43.4 & 43.4 & 0 & 0 & 0 & 0 \\
\hline 21 & 411 & 411.9 & 425.1 & 425.1 & 127.9 & 104 & $\begin{array}{l}69.8 \\
\end{array}$ & 130 & 89.9 & 129 & 68.1 & 64 & 72.1 & 72.1 & 0 & 0 & 0 & 0 & 0 & 0 \\
\hline 22 & 396.6 & 397.5 & 334.1 & 421.4 & 120.2 & 0 & 82.1 & 123.2 & 0 & 96 & 52.1 & 66.6 & 55.1 & 55.1 & 0 & 0 & 0 & 0 & 0 & 0 \\
\hline 23 & 451.6 & 383.1 & 417.7 & 417.6 & 130 & 0 & 0 & 0 & 0 & 0 & 0 & 0 & 0 & 0 & 0 & 0 & 0 & 0 & 0 & 0 \\
\hline 24 & 414 & 445.4 & 326.7 & 413.9 & 0 & 0 & 0 & 0 & 0 & 0 & 0 & 0 & 0 & 0 & 0 & 0 & 0 & 0 & 0 & 0 \\
\hline
\end{tabular}


All decimals are rounded off to the nearest integers for all power values.

The unit status along with the generation level for 20-unit system in the presence of ramp rate limit determined using BARON solver considering valve point coefficients is shown in Table 5. Here, unit 1 to unit 4 are in ON state continuously for complete 24-hour time period. Unit 5 is $\mathrm{ON}$ at hour $5^{\text {th }}$ to hour $23^{\text {rd }}$ due to minimum up and minimum down time constraints. Unit 6 turns ON with BARON solver during hour $8^{\text {th }}$ to hour $21^{\text {st }}$ while unit 7 and unit 8 are also in ON state at $6^{\text {th }}, 7^{\text {th }}$ and $22^{\text {nd }}$ time interval. Unit 9 keeps itself ON from $3^{\text {rd }}$ to $21^{\text {st }}$ time interval continuously. Unit 10 remains $\mathrm{ON}$ from hour $4^{\text {th }}$ to hour $22^{\text {nd }}$. Units 11 and 12 are $\mathrm{ON}$ from time interval 9 to interval 14 and also remain $\mathrm{ON}$ during hours $20^{\text {th }}, 21^{\text {st }}$ and $22^{\text {nd }}$. Unit 13 has same status like unit 11 and 12 but the difference is that it keeps OFF at hour $14^{\text {th }}$. Coming to unit 14 , it keeps itself $\mathrm{ON}$ at hour $10^{\text {th }}$ to hour $14^{\text {th }}$ and also at hour $20^{\text {th }}, 21^{\text {st }}$ and $22^{\text {nd }}$. Unit 15 keeps ON at hour $10^{\text {th }}$ and hour $12^{\text {th }}$ and also ON at hour $20^{\text {th }}$, while unit 16 keeps ON at hour $10^{\text {th }}$ to $13^{\text {th }}$ and hour $20^{\text {th }}$. Unit 17 is $\mathrm{ON}$ at hours $11^{\text {th }}$ and $12^{\text {th }}$ because of high load demand during these time intervals. Unit 18 keeps ON from hour $11^{\text {th }}$ to $13^{\text {th }}$, and unit 19 is ON at hour $11^{\text {th }}$ and unit 20 is $\mathrm{ON}$ at hour $11^{\text {th }}$ and hour $12^{\text {th }}$. The ON-OFF status of various units by the proposed approach resulted in optimal operating cost while satisfying all the constraints so as to keep the power mismatch to zero. The start-up cost obtained under this operating scenario is Rs. 9070. Figures 6(a) and 6(b) illustrate the electric energy generated during the day and total operating cost versus number of thermal generating units respectively. Figure 6(a), shows that the units 1, 2, 3 and 4 generate maximum power with and without ramp rate limits and are utilized throughout the day. The energy obtained for unit $1,2,3,4,5,6,7,8,9$ and 10 in the absence of ramp limits is 10343,10242.7, 9597.1, 9615.6, 1937.1, 1974.8, 1932, 1675.8, 2501.3 and 2278.4 MWh, respectively. Similarly, energy obtained in the presence of ramp rate limit is 10150.3, 10278.5, 9660.2, 9566.4, 2050.1, 1565.3, 1968.9, 1908.4, 2167.9 and $2515 \mathrm{MWh}$, respectively. In the absence of ramp rate unit 11,12, 13, 14, 15, 16, 17, 18, 19 and 20 has 228.3, 492.8, 354, 466.5, $217,151,30,75.8,43.4$ and 43.4 MWh of energy, respectively. Likewise, energy obtained in the presence of ramp limits for unit $11,12,13,14,15,16,17,18,19$ and 20 is 514.7, 539.2, 447.3, $356.5,101.4,151.1,75.8,97.2,10$ and 75.8 MWh, respectively. It is observed from Figure 6(a), that 4 units i.e. unit 1 , unit 2 , unit 3 and unit 4 generate maximum energy among all units. The energy generated by these four units is $39798.2 \mathrm{MWh}$, which is $73.42 \%$ of the total energy generated by all the units taken together over a day in the absence of ramp rate limits. It is also observed from Figure 6(a), that 4 units i.e. unit 1, unit 2, unit 3 and unit 4 generate maximum energy among all units. The energy generated these four units is $39655.45 \mathrm{MWh}$, which is $73.16 \%$ of the total energy generated by all the units taken together over a day in the presence of ramp rate limits. This result is obvious as these are large sized units having higher efficiency. Total operating cost result for other units without ramp rate limits is Rs. 573043 for 10-unit, Rs. 2281027 for 40 -unit, Rs. 3388526 for 60 -unit, Rs. 4474203 for 80-unit and Rs. 5716453 for 100 units, respectively. Likewise, cost result for other units with ramp rate constraint is Rs. 581274 for 10-unit, Rs. 2297755 for 40-unit, Rs. 3398936 for 60-unit, Rs. 4578412 for 80-unit and Rs. 5754456 for 100 units, respectively. Hence, from Figure 6(b), it can be observed that the cost increases linearly as the system size increases with and without ramp rate constraints. It is clearly seen from Figures 7(a) and 7(b), that available maximum rated capacity of units closely follows the demand with spinning reserve curve except 15-19 hours where minimum up and down time constraints of some units are binding. 


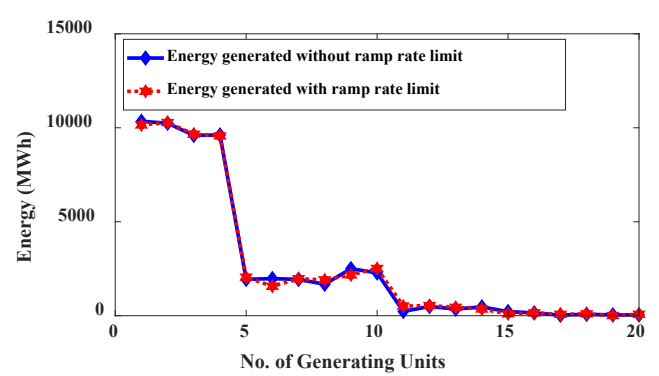

(a)

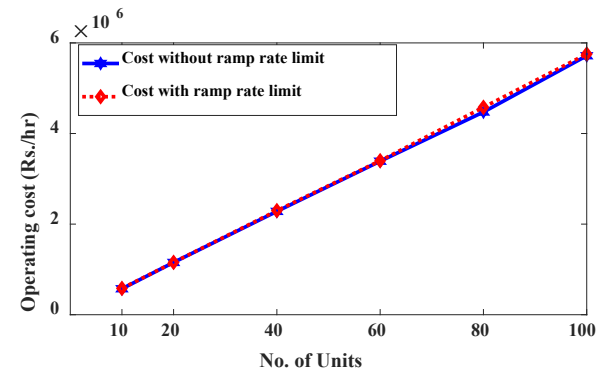

(b)

Figure 6. Optimum UC schedule for 20-unit, 24-h test system for Case study 2 (a) Energy generated with and without ramp rate limit by each unit per day (b) Operating cost vs no. of generating units.

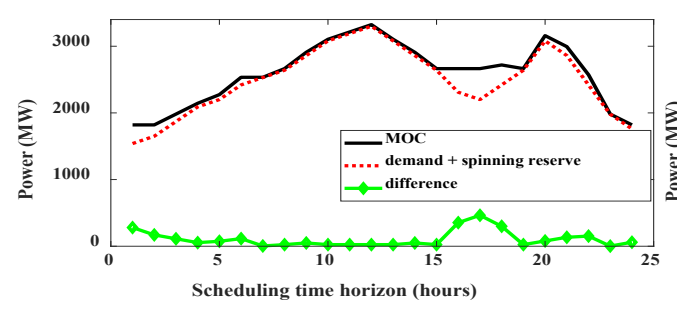

(a)

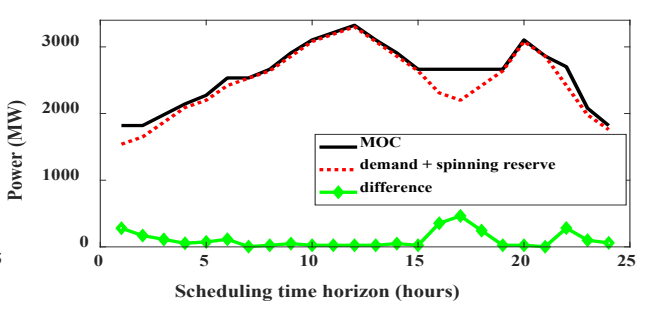

(b)

Figure 7. Comparison between available total online capacity of units and demand considering spinning reserve for the 20-unit, 24-hour system for Case study 2 (a) without ramp rate constraints (b) with ramp rate constraints

In all the case studies it has been found that the BARON software has terminated when relative gap equals zero.

The other limits defined for terminating criteria were never reported during the execution of BARON software.

\section{Conclusion}

In this paper, the BARON solver has been applied successfully to model and solve the CBUC problem in two different scenarios. Firstly, CBUC problem with quadratic cost function and thereafter the same problem with valve point loading effect with and without ramp rate limits of thermal units has been solved. The simulation results clearly reveal that BARON solver produces qualitative cost solutions without any constraint violation and it has been observed from the results that there is a significant improvement in the cost results obtained as compared to the results obtained by modified novel binary artificial bee colony with genetic crossover (MBABCGC) algorithm. It can also be seen that for a test system, BARON produces the same solution at each run of the software whereas after every run of the metaheuristic algorithm results in a different solution. The unit commitment results obtained using the BARON solver can be used as benchmark results in future research work in this area.

\section{Acknowledgment}

This work has been sponsored by the Council of Scientific and Industrial Research (CSIR), New Delhi, India under project grant 22(0815)/19 / EMR-II of the Human Resources Development Group, sanctioned to second author.

\section{References}

[1]. Wood A.J. and Wollenberg B. F., "Power Generation, Operation and Control," $2^{\text {nd }} e d$., Wiley: New York, pp.131-166, 2007. 
[2]. Ouyang Z. and Shahidehpour S.M., "An intelligent dynamic programming for unit commitment application," IEEE Trans. Power Syst., vol.6, no. 3, pp. 1203-1209,1991.

[3]. Senjyu, T., Shimabukuro K., Uezato K. and Funabashi T., "A fast technique for unit commitment problem by extended priority list," IEEE Trans. Power Syst., vol.18, no.2, pp.882-888, 2003.

[4]. Li X., Li T., Wei J., Wang G. and Yeh W. W. G., "Hydro unit commitment via mixed integer linear programming: a case study of the three gorges project China," IEEE Trans. Power Syst., vol.29, no. 3, pp. 1232-1241, 2014.

[5]. Viana A. and Pedroso J. P., "A new MILP-based approach for unit commitment in power production planning," Int. J. Electric. Power Energy Syst., vol.44, pp. 997-1005, 2013.

[6]. Feng X. and Liao Y., "A new lagrangian multiplier update approach for Lagrangian relaxation-based unit commitment," Electr. Power Compon. Syst., vol.34, pp. 857-866, 2006.

[7]. Chen C.L. and Wang S.C., "Branch-and-bound scheduling for thermal generating units, " IEEE Trans. Energy Convers., vol.8, no.2, pp. 184-189, 1993.

[8]. Kazarlis S.A., Bakirtzis, A.G. and Petridis V., "A genetic algorithm solution to the unit commitment problem," IEEE Trans. Power Syst., vol. 11, no.1, pp. 83-92, 1996.

[9]. I.G. Damousis, A.G. Bakirtiz and P.S. Dokopolus, "A solution to the unit commitment problem using integer coded genetic algorithm," IEEE Trans, Power Syst., vol. 19, pp. 1165-1172, 2004.

[10]. L. Sun, Y. Zhang and C. Jiang, "A matrix real coded genetic algorithm to the unit commitment problem," Electr. Power Syst. Res., vol.76, pp.716-728,2006.

[11]. Juste K.A., Kita H., Tanaka E. and Hasegawa J., "An evolutionary programming solution to the unit commitment problem," IEEE Trans. Power Syst., vol.14, no.4, pp.1452-1459, 1999.

[12]. M.N.C. Othman, T.K.A. Rahman, H. Mokhlis and M.M. Aman, "Solving unit commitment problem using multi-agent evolutionary programming incorporating priority list," Arab J. Sci, Eng., vol. 40, pp. 3247-3261, 2015.

[13]. Simopoulos D. N., Kavatza S.D. and Vournas C.D., "Unit commitment by an enhanced simulated annealing algorithm," IEEE Trans. Power Syst., vol. 21, no.1, pp.68-76, 2006.

[14]. Arif S., Mohammedi R., Hellal A. and Choucha A., "A memory simulated annealing method to the unit commitment problem with ramp constraints," Arab. J. Sci. Eng., vol. 37, pp.1021-1031, 2012.

[15]. Uyar A.S. and Turkay B., "Evolutionary algorithms for the unit commitment problem," Turk. J. Elec. Eng., vol.16, no.3, pp.239-255, 2008.

[16]. Yuan X., H. Nie, A., Su, L. Wang and Y. Yuan, "Application of enhanced discrete differential evolution approach to unit commitment problem," Energy convers. Manag., vol. 50, pp. 2449-2456, 2009.

[17]. Lau T.W., Chung C.Y., Wong K.P., Chung T.S. and Ho S.L., "Quantum-inspired evolutionary algorithm approach for unit commitment," IEEE Trans. Power Syst., vol. 24, no.3, pp. 1503-1512, 2009.

[18]. Eslamian M., Hosseinian S.H. and Vahidi B., "Bacterial foraging-based solution to the unit commitment problem," IEEE Trans. Power Syst., vol. 24, no.3, pp. 1478-1488, 2009.

[19]. J. Ebrahimi, S.H. Hosseinian and G.B. Gharehpetian, "Unit commitment problem solution using shuffled frog leaping algorithm," IEEE Trans. Power Syst., vol. 26, pp. 573-581, 2011.

[20]. Hadji M.M. and Vahidi B., "A solution to the unit commitment problem using imperialistic competition algorithm," IEEE Trans. Power Syst., vol. 27, no.1, pp. 117-124, 2012.

[21]. Khorasani J., "A new heuristic approach for unit commitment problem using particle swarm optimization," Arab. J. Sci. Eng., vol. 37, pp. 1033-1042, 2012.

[22]. D.F. Rahman, A. Viana and J.P. Pedroso, "Metaheuristic search-based methods for unit commitment," Int. J. Electric Power Energy Syst., vol.59, pp.14-22, 2014. 
[23]. X. Yuan, H. Nie, A. Su, L. Wang and Y. Yuan, "An improved binary particle swarm optimization for unit commitment problem," Expert Syst. Appl., vol.36, pp.8049-8055, 2009.

[24]. Najafi A., Farshad M. and Falagi H., "A new heuristic method to solve unit commitment by using time variant acceleration coefficients particle swarm optimization algorithm," Turk. J Elec. Eng. \& Comp. Sci., vol.23, pp. 354-369, 2015.

[25]. Pourjamal Y. and Ravadanegh S. N., "HSA based solution to the UC problem," Int. J. Electr. Power Energy Syst., vol. 46, pp. 211-220, 2013.

[26]. Saleem N., Ahmad A. and Zafar S., "A modified differential evolution algorithm for the solution of a large-scale unit commitment problem," Arab. J. Sci. Eng., vol. 39, pp. 88898900, 2014.

[27]. Saravanan B., Vasudevan E.R. and Kothari, D.P., "Unit commitment problem solution using invasive weed optimization algorithm," Int. J. Electr. Power Energy Syst., vol. 55, pp. 21-28, 2014.

[28]. Yuan X., Ji B., Zhang S., Tian H. and Hou Y., "A new approach for unit commitment problem via binary gravitational search algorithm," Appl. Soft Comput., vol. 22, pp. 249$260,2014$.

[29]. Wang C. and Shahidehpour S. M., "Effects of ramp-rate limits on unit commitment and economic dispatch," IEEE Trans. Power Syst., vol.8, no.3, pp. 1341-1350, 1993.

[30]. Patra S., Goswami S.K. and Goswami B., "Fuzzy and simulated annealing based dynamic programming for the unit commitment problem," Exp. Syst. Appl., vol. 36, pp.5081-5086, 2009.

[31]. Abarghooee R. A., Niknam T., Bavafa F. and Zare M., "Shortterm scheduling of thermal power systems using hybrid gradient based modified teaching-learning optimizer with black hole algorithm," Electr. Power Syst. Res., vol. 108, pp. 16-34, 2014.

[32]. Kang W.Y., Cheng, H.C. and Liang L.C., "Resolution of the unit commitment problems by using the hybrid Taguchi-ant colony system algorithm," Int. J. Electr. Power Energy Syst., vol. 49, pp.188-198, 2013.

[33]. T. Niknam, A. Khadaei and F. Fallahi, "A new decomposition approach for the thermal unit commitment problem," Applied Energy, vol. 86, pp.1667-1674, 2008.

[34]. Karaboga D. and Basturk B., "A powerful and efficient algorithm for numerical function optimization: artificial bee colony (ABC) algorithm," J. Global Optim., vol. 39, pp. 459$471,2007$.

[35]. Chandrasekaran K., Hemamalini S., Simon, S. P. and Padhy N. P., "Thermal unit commitment using binary/real coded artificial bee colony algorithm," Electr. Power Syst. Res., vol. 84, pp.109-119, 2012.

[36]. Prateek K. Singhal, R. Naresh and Veena Sharma, "A Novel Strategy-Based Hybrid Binary Artificial Bee Colony Algorithm for Unit Commitment Problem,” Arab J Sci Eng., vol. 40, pp.1455-1469, 2015.

[37]. Prateek K. Singhal, R. Naresh and Veena Sharma, "A modified binary artificial bee colony algorithm for ramp rate constrained unit commitment problem," Int. Trans. Electr. Energy Syst., vol. 25, pp. 3472-3491, 2015.

[38]. Debabrata Chattopadhyay, "Application of General Algebraic Modelling system to power system optimization," IEEE transactions on Power systems, vol. 14, no.1, pp.15-22, 1999.

[39]. B. Padmanabham, J. Jasper M.E. and Siva Kumar R.S., "Bee Hive algorithm to optimize multi constrained piecewise nonlinear economic dispatch problem in thermal units," International Journal on Electrical Engineering and Informatics, vol. 3, no.1, pp.109-117, 2011.

[40]. Benayed Fatima Zohra, Abdelhakem Koridak Lahouari and Rahli Mostefa, "An Improved Harmony Search Algorithm for solved the combined Heat and Power Economic Dispatch," International Journal on Electrical Engineering and Informatics, vol. 11, no.2, pp.440$450,2019$. 
[41]. Benayed Fatima Zohra, Abdelhakem Koridak Lahouari and Rahli Mostefa, "An Improved Harmony Search Algorithm for solved the combined Heat and Power Economic Dispatch," International Journal on Electrical Engineering and Informatics, vol. 11, no.2, pp.440-450, 2019.

[42]. Sichard E. and Rosenthal, "GAMS, A User's Guide," Tutorial GAMS Development Corporation, Washington, 2010.

[43]. Nick Sahinidis, "BARON user manual," The Optimization Firm, LLC, USA, 2018.

Appendix

Data for 20-unit test system considering quadratic cost characteristics

\begin{tabular}{|c|c|c|c|c|c|c|c|c|c|c|c|}
\hline $\begin{array}{l}\text { Unit } \\
\text { (i) }\end{array}$ & $\begin{array}{l}P_{i}^{\max } \\
(M W)\end{array}$ & $\begin{array}{l}P_{i}^{\min } \\
(M W)\end{array}$ & $\begin{array}{c}a_{i} \\
(R s / h r)\end{array}$ & $\begin{array}{c}b_{i} \\
(R s / M W h)\end{array}$ & $\begin{array}{c}c_{i} \\
\left(R s / M W^{2} h\right)\end{array}$ & $\begin{array}{c}I N I_{i} \\
\text { (h) }\end{array}$ & $\begin{array}{c}T_{i, u p} \\
\text { (h) }\end{array}$ & $\begin{array}{c}T_{i, \text { down }} \\
\text { (h) }\end{array}$ & $\begin{array}{c}H S C i \\
(R s)\end{array}$ & $\begin{array}{c}C S C i \\
(R s)\end{array}$ & $\begin{array}{l}T_{i, \text { cold }} \\
\text { (h) }\end{array}$ \\
\hline 1,2 & 455 & 150 & 1000 & 16.19 & 0.00048 & 8 & 8 & 8 & 4500 & 9000 & 5 \\
\hline 3,4 & 455 & 150 & 970 & 17.26 & 0.00031 & 8 & 8 & 8 & 5000 & 10000 & 5 \\
\hline 5,6 & 130 & 20 & 700 & 16.60 & 0.002 & -5 & 5 & 5 & 550 & 1100 & 4 \\
\hline 7,8 & 130 & 20 & 680 & 16.50 & 0.00211 & -5 & 5 & 5 & 560 & 1120 & 4 \\
\hline 9,10 & 162 & 25 & 450 & 19.70 & 0.00398 & -6 & 6 & 6 & 900 & 1800 & 4 \\
\hline 11,12 & 80 & 20 & 370 & 22.26 & 0.00712 & -3 & 3 & 3 & 170 & 340 & 2 \\
\hline 13,14 & 85 & 25 & 480 & 27.74 & 0.00079 & -3 & 3 & 3 & 260 & 520 & 2 \\
\hline 15,16 & 55 & 10 & 660 & 25.92 & 0.00413 & -1 & 1 & 1 & 30 & 60 & 0 \\
\hline 17,18 & 55 & 10 & 665 & 27.27 & 0.00222 & -1 & 1 & 1 & 30 & 60 & 0 \\
\hline 19,20 & 55 & 10 & 670 & 27.79 & 0.00173 & -1 & 1 & 1 & 30 & 60 & 0 \\
\hline
\end{tabular}

Data for 20-unit test system considering valve point coefficients

\begin{tabular}{|c|c|c|c|c|c|c|c|c|c|c|c|c|c|}
\hline Unit (i) & $\begin{array}{l}P_{i}^{\max } \\
(M W\end{array}$ & $\begin{array}{c}P_{i}^{\min } \\
(M W)\end{array}$ & $\begin{array}{c}a_{i} \\
(R s / h r)\end{array}$ & $\begin{array}{c}b_{i} \\
(R s / M W h)\end{array}$ & $\begin{array}{c}c_{i} \\
\left(R s / M W^{2} h\right)\end{array}$ & $\begin{array}{c}e_{i} \\
(R s / h r)\end{array}$ & $\begin{array}{c}f_{i} \\
(\mathrm{Rad} / \\
M W)\end{array}$ & $\begin{array}{l}I N I_{i} \\
\text { (h) }\end{array}$ & $\begin{array}{l}T_{i, u p} \\
\text { (h) }\end{array}$ & $\begin{array}{l}T_{i, \text { down }} \\
\text { (h) }\end{array}$ & $\begin{array}{c}H S C i \\
(R s)\end{array}$ & $\begin{array}{c}C S C i \\
(R s)\end{array}$ & $\begin{array}{c}T_{i, \text { cold }} \\
\text { (h) }\end{array}$ \\
\hline 1,2 & 455 & 150 & 1000 & 16.19 & 0.00048 & 450 & 0.041 & 8 & 8 & 8 & 4500 & 9000 & 5 \\
\hline 3,4 & 455 & 150 & 970 & 17.26 & 0.00031 & 600 & 0.036 & 8 & 8 & 8 & 5000 & 10000 & 5 \\
\hline 5,6 & 130 & 20 & 700 & 16.60 & 0.002 & 300 & 0.086 & -5 & 5 & 5 & 550 & 1100 & 4 \\
\hline 7,8 & 130 & 20 & 680 & 16.50 & 0.00211 & 340 & 0.082 & -5 & 5 & 5 & 560 & 1120 & 4 \\
\hline 9,10 & 162 & 25 & 450 & 19.70 & 0.00398 & 310 & 0.048 & -6 & 6 & 6 & 900 & 1800 & 4 \\
\hline 11,12 & 80 & 20 & 370 & 22.26 & 0.00712 & 270 & 0.098 & -3 & 3 & 3 & 170 & 340 & 2 \\
\hline 13,14 & 85 & 25 & 480 & 27.74 & 0.00079 & 270 & 0.098 & -3 & 3 & 3 & 260 & 520 & 2 \\
\hline 15,16 & 55 & 10 & 660 & 25.92 & 0.00413 & 380 & 0.094 & -1 & 1 & 1 & 30 & 60 & 0 \\
\hline 17,18 & 55 & 10 & 665 & 27.27 & 0.00222 & 380 & 0.094 & -1 & 1 & 1 & 30 & 60 & 0 \\
\hline 19,20 & 55 & 10 & 670 & 27.79 & 0.00173 & 380 & 0.094 & -1 & 1 & 1 & 30 & 60 & 0 \\
\hline
\end{tabular}


Load demand for Case 1 and Case 2 for 24 time period for 20-unit system

\begin{tabular}{|l|c|c|c|c|c|c|c|c|c|c|c|c|}
\hline Hour & 1 & 2 & 3 & 4 & 5 & 6 & 7 & 8 & 9 & 10 & 11 & 12 \\
\hline Load (MW) & 1400 & 1500 & 1700 & 1900 & 2000 & 2200 & 2300 & 2400 & 2600 & 2800 & 2900 & 3000 \\
\hline Hour & 13 & 14 & 15 & 16 & 17 & 18 & 19 & 20 & 21 & 22 & 23 & 14 \\
\hline Load (MW) & 2800 & 2600 & 2400 & 2100 & 2000 & 2200 & 2400 & 2800 & 2600 & 2200 & 1800 & 1600 \\
\hline
\end{tabular}

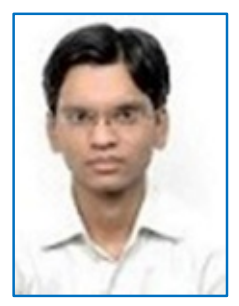

Vineet Kumar born in Lucknow in 1991. He received his B. Tech. Degree in Electrical and Electronics Engineering from ABES Engineering College, Ghaziabad, India in 2013, the M. tech degree in Power System from NIT Hamirpur, India in 2017. He is currently a research scholar in Electrical Engineering Department, NIT Hamirpur, India. He is working in Unit Commitment area of power system.

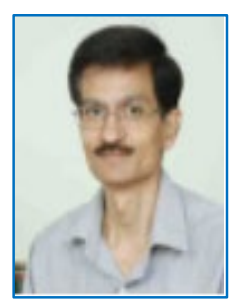

R. Naresh born in 1965, in Himachal Pradesh India. He graduated in 1987 from Thapar Institute of Engineering and Technology, Patiala, India with a BE degree in Electrical Engineering, post graduate (M. Tech in Power System) from Punjab Engineering College, Chandigarh in 1990 and doctoral degree (Ph.D.) in 1999 from IIT Roorkee, India. He is currently serving as a professor in the Department of Electrical Engineering, National Institute of Technology, Hamirpur, India. His area of expertise includes applications of AI techniques, evolutionary and recent heuristic optimization techniques, helpful in modern power system planning, operation and control. 